Academic Voices

A Multidisciplinary Journal

Volume 6, No. 1, 2016

ISSN 2091-1106

\title{
WILD ECOLOGY OF SPOTTED DEER (Axis axis)
}

\author{
Pramod Kumar Kush waha \\ Department of Zoology, TU, Thakur Ram M ultiple Campus, irgunj, Nepal \\ Email: pramodkushwahatrm1@gmail.com
}

\begin{abstract}
Chital occur in Nepal throughout the Terai lowland and \& adjoining Siwalik hills up to an altitude of 200 meters. It is widely distributed and abundant in Terai protected areas of Nepal Chital is generally found in st and dry deciduous forests. The species displays a number of preferences which influence its distribution. Four factors are limited for Chital: nee for water, need for shelter, avoidance of high rugged terrain, and the preference for grass as forage. Chital drink water at least once a day and usually twice a day during summer, which under dry conditions would tend to localize the animals around the waterhole.
\end{abstract}

\section{Key words}

Chital; simplespikes; three tined antlers; adult bucks; fawns

\section{Introduction}

Spotted deer (Axis axis) is locally called chital. Chital is considered to be among the most primitive of the cervids (Flerow, 1960). The Chital is medium-sized deer standing about 0.90 to 12 meters high at the shoulder. One adult stag weighed about 60 kilograms. The first set of antlers in yearlings consists of simplespikes; adults carry three-tined antlers.

The chital spend major portion of their life in foraging, resting and wandering within their range. During the cool season, the Chital become active at or just before sun up and graze. Feeding if any in day time is usually cursory. As the days grow hotter the Chital spend most of the daylight hours in the shade.
In general, Chital have 2 major rest periods, one in the hours before dawn and the other from mid morning to mid afternoon. Peak feeding occurs for about 2 hours after dawn and one hour before and after dusk.

The government of Nepal/ Council of ministers has approved to establish Deer Research Centre (DRC) in Godawari, Lalitpur on 199112.02 by taking 10 hectares of forest land on lease. The construction works started in January 1993, and research commenced since December, 1993. Thework was started in accordancewith theagreement made between Department of National Parks and Wildlife Conservation (DNPWC)/ Government of Nepal and Veterinary Department of Sydney 
University, Australia. The centrewas managed by DNPWC since its establishment and since F/Y 2004/ 05 (2061/062), it is being managed by ShNP (DNPWC, 2007a,b).

\section{Materials and methods}

To take the ecological information about spotted deer I visited separately the Deer Research Center (DRC) Godawari, the zoo of Jawalakhel KTM, Chitwan national Park, Bardia National Park, Parsa Wildlife Reserve and Shivpani National Park. Knowledge of ecology is particularly crusial specially in the species translocation. In order to select the suitable release site to choose ideal social structure of release stock, to compare and contrast their behavior in capativity and in natural habitat, it is essential to know the ecology of species.

\section{Results and discussions}

The pattern of herd formation is either a loose flock or a single file. Chital visit waterholes usually twice a day at about sunrise and in the late afternoon. They approach a waterhole cautiously and in herd.

Home range in deer is usually two kilometer in diameter and movements is influenced by daily and seasonal changes in the quality and quantity of life's requirements with rutting bucks roaming more widely than does.

Chital associate with most other animals particularly with other ungulates. Mixed herds of Chital and Barahsingha are common on Suklaphanta, Chitwan and Bardia National Parks. Chital also mingled freely with Sambar and sometimes with hog deer, Nilgai and wild boar. Langur monkeys and chital are associated when langur feed on a tree, chital crowd beneath it and pick up the leaves and fruits dropped by monkeys. Mynah birds perch on the back of the chital and appear to search for ectoparasites. Black drongos sit on their head and snag insects flushed by their hooves. Jungle crows pull strips of velvet from the antler of the bucks. The chital, whose senses of smell and hearing are excellent but whose sight is often not sufficiently acute, has complemented its perpetual world considerably by relying in part on other animals. The chital give alarm call at the sight of a predator.

Chital eat both grass and browse, with the former providing the bulk of their diet at all seasons. Their favored forage is short green grass. Browse includes the leaves from a number of trees, shrubs and vines. As many as 44 species of grasses and 35 browse species wereeaten by Chital at Kanha (Schaller, 2004).

Adult bucks shed their antlers yearly. The antlers are dropped at intervals of roughly 10 to 12 months. Studies have revealed that the antlers are lost after the nit and the new growth is completed to coincide with the onset of the next rutting period. Animals that have just lost their antlers can be classified as being in velvet. Most of the bucks shed their antlers between August and October. Most studies have shown that the gestation period is 6 months whereas others indicated up to 8.5 months. A doe usually bears single fawn at a time. Captive Chital does have a continuous series of diestrous cycle lasting about 3 weeks throughout the year (Schaller 2004). The animals are therefore able to conceive during any month since bucks in rutting condition are also present at all times. It seems probable that does which have lost their small fawns through predation or other means come into estrus again soon afterward. Thus, the potential annual production of fawns $b$ a Chital doe is generally one. There are alltogether 157 deers in DRC Godawari as on October, 2008 (Table 1).

Table 1: Animals in Deer Research Centre Godawari Lalitpur (Octo ber, 2008)

\begin{tabular}{llll}
\multicolumn{1}{c}{ Species } & \multicolumn{1}{c}{ Male } & Female & \multicolumn{1}{c}{ Total } \\
Musk Deer & 0 & 1 & 1 \\
\hline Barking Deer & 10 & 16 & 26 \\
\hline Spotted Deer & 41 & 89 & 130 \\
\hline Total & 51 & 106 & 157 \\
\hline
\end{tabular}


Initial fawns production remains rather stable, except in unusual circumstances, butmortality may vary considerably fomi year to year. Possible causes of mortality include accidents, diseases and redation. Predation is the major cause of mortality (Schaller, 2004).

Pedicels become visible by the age of about $\mathbb{D}$ months and then grow into spikes, which are shed at the age of about 20-22 months. Any buck which has lost its spike is considered to be an adult. The adult bucks can be segregated into several classes based on antler length, however Severinghans and Cheatum, 1956 (quoted by Schaller, 2004) showed that antlers size is a poor criterion for determining age in Deer.

The bucks associate closely with the does during and following the peak of the rut from May to July. Schaller (2004) observed that most fawns were born between January and May in Kanha.

Agonistic interaction between bucks, sexual relations between bucksand does and between female and young relation sare prevalent. The chital is a group living animal, average size vary considerably with the season ranging from 5 and 10 animals to hundreds per herd. Bucks, does and fawns associates throughout the year. Although the composition of herd is usually mixed, chital have a tendency to form buck herds and herds consisting of does with small fawns. The composition of chital herds changes constantly. Bucks in velvet are very passive.

\section{Acknowledgements}

I would like to thank the staff of Deer Research Centre Godawari, Shivapuri National Park and Parsa Wildlife Reserve. I am grceful to Dr. Nagendra MB Pradhan planning officer,DNPWC and Mr. Kishor K. Mehta Assistant Conservation Officer Shivapuri National Park.

\section{References}

DNPWC (2007a). Rhino Status Monitoring in Bardia National park. Wildlife Nepal Newsletter, 179(12).

DNPWC (2007b). Increasing Trend of Blackbucks in Nepal (in Nepali). Sam rakshan samachar, 27(3).

Flerow, K. (1960). Fauna of USSR: Musk Deer and Deer. Washington DC: Israel Program for Scientific Translations.

Schallar, G. B. (2004). The Deer and the Tiger: A Study of Wildlife in India. Natraj Publishers, Dehradun, India 